\title{
Different root growth patterns of tomato seedlings grown hydroponically under an electric field
}

\author{
Giuseppe Tataranni ${ }^{1}$, Adriano Sofo ${ }^{1}$, Cristiano Casucci $^{2}$ and Antonio Scopa ${ }^{1}$ \\ ${ }^{1}$ Scuola di Scienze Agrarie, Forestali, Alimentari ed Ambientali, Università degli Studi della Basilicata, Via \\ dell'Ateneo Lucano 10, 85100 Potenza, Italy. \\ 2 Dipartimento di Scienze Agrarie, Alimentari ed Ambientali - D3A, Università Politecnica delle Marche, Piazza \\ Roma 22, 60121 Ancona, Italy. \\ Corresponding author: A. Sofo, E. mail: adriano.sofo@unibas.it, Phone+39-0971-206228, \\ Fax +39-0971-205378
}

Received on May 19, 2012; Accepted on March 11, 2013

\begin{abstract}
Electric fields can determine changes at morphological and physiological levels in plants. In this study, seedlings of Solanum lycopersicum L., grown hydroponically in a floating system, were exposed to a DC $12.0 \mathrm{~V}$ $\mathrm{m}^{-1}$ electric field (EF). Root morphology was strongly affected by the electric field applied and a significant variation in root growth rate was observed along the gradient. The tomato plants grown on the hand of the positive electrode showed a pronounced length, root hairs' development and root branching, compared to the plants grown at the central area of the container and on the hand of the negative electrode. Root growth of the control plants not exposed to the EF resembled that of EF-exposed plants taken in the central area. Hypotheses according to which the different growth patterns observed could be related to a chemiosmoticinduced activity and/or the distribution of plasma membrane carriers are discussed. In conclusion, the root growth was affected by the positions under application of EF. The results point to a possibility of applying electric fields for controlling tomato root growth.
\end{abstract}

Keywords: Solanum lycopersicum L., DC electric field, root morphology, growth rate, microscopy

\section{Introduction}

Capabilities for environmental stress perception, signaling, and response of plant species have a great range of variability. The application of an electric field can affect directly or indirectly the organisms exposed to it, inducing a series of responses. Electric fields (EFs) have been tested in several instances with contradictory results, depending on the strength applied, the substrate in which roots grow, and plant sensitivity. Several experiments have been carried out in liquid media (Wolverton et al. 2000), hydroponic conditions or artificial soil (Nechitailo and Gordeev 2004). The root meristem architecture (Wawrecki and Zagórska-Marek 2007), as well as the development of lateral roots, was proved to be affected by EFs (Hamada et al. 1992). An EF seems to induce changes in cell membrane potential of the root, although the exact nature of these changes is difficult to predict (Ishikawa and Evans 1990). Chemiosmotic gradient and/or auxin might play a role in the ultimate establishment of the differential growth pattern that various papers underline (Robinson 1985).

In our previous results, Scopa et al. (2009) observed that Arundo donax seedlings exposed to a DC $\mathrm{EF}$ of $12.0 \mathrm{~V} \mathrm{~m}^{-1}$ showed a significant increase in growing rate of both shoots and roots. On this basis, the aim of this work is to estimate the effect of a DC EF on developing roots of tomato seedlings grown in a hydroponic floating system under controlled conditions, in consideration of a possible applicative technique for controlling root development in this important cultivated species. In this experimentation, modifications in root growth rate and morphology were examined and evaluated.

\section{Materials and Methods}

\section{Plant material and experimental design}

Seeds of Solanum lycopersicum L. were sterilized in a solution of $5 \%(\mathrm{v} / \mathrm{v}) \mathrm{NaOCl}$, rinsed three times with $95 \%$ ethanol, washed with distilled water and then put in an inorganic mineral base of sterile sand as solid substrate. The experiment was realized in a floating

Tataranni G, Sofo A, Casucci C, Scopa A 2013 Different root growth patterns of tomato seedlings grown hydroponically under an electric field. Plant Root 7:28-32. doi:10.3117/plantroot.7.28

Copyrights 2013, Plant Root (JSRR), www.plantroot.org 
polystyrene vessel with 96 holes (characteristics in Fig. 1). A number of 192 plants (2 plants per hole) were grown hydroponically in $1 / 4$-strength Hoagland liquid medium $\left[2.53 \mathrm{mM} \mathrm{KNO}_{3}, 0.75 \mathrm{mM} \mathrm{Ca}\left(\mathrm{NO}_{3}\right)_{2} \cdot 4 \mathrm{H}_{2} \mathrm{O}\right.$, $0.50 \mathrm{mM} \mathrm{NH} \mathrm{H}_{2} \mathrm{PO}_{4}, 0.50 \mathrm{mM} \mathrm{MgSO}{ }_{4} \cdot 7 \mathrm{H}_{2} \mathrm{O}, 4.10$ $\mathrm{mM} \mathrm{FeSO} \cdot 7 \mathrm{H}_{2} \mathrm{O}, 2.03 \mathrm{mM} \mathrm{Na}$-EDTA, $11.58 \mathrm{mM}$ $\mathrm{H}_{3} \mathrm{BO}_{3}, 2.28 \mathrm{mM} \mathrm{MnCl}_{2} \cdot 4 \mathrm{H}_{2} \mathrm{O}, 0.08 \mathrm{mM} \mathrm{CuSO}_{4} \cdot 5 \mathrm{H}_{2} \mathrm{O}$, $0.15 \mathrm{mM} \mathrm{H}_{2} \mathrm{MoO}_{4} \mathrm{H}_{2} \mathrm{O}, 0.40 \mathrm{mM} \mathrm{ZnSO}{ }_{4} \cdot 7 \mathrm{H}_{2} \mathrm{O}$ ]. After 10 days from the germination, one seedling was removed and only the best one was kept alive. Seedlings were maintained under controlled conditions at a constant temperature of $20^{\circ} \mathrm{C}$ with a $16 \mathrm{~h}$ photoperiod and a PAR of $350 \mu \mathrm{mol} \mathrm{m} \mathrm{m}^{-2} \mathrm{~s}^{-1}$ (measured at vessel level $=1 \mathrm{~m}$ from the lamps). The light source was a fluorescent lamp providing the spectrum plants need for photosynthesis (model Pioneer T5; Hydroempire, CA, USA). Throughout the experiment, temperature and solution volume were maintained constant.

Two parallel stainless steel plates (width $=30 \mathrm{~cm}$; height $=15 \mathrm{~cm}$; thickness $=0.2 \mathrm{~cm}$ ) were placed in the medium, and they work as electrodes. After 17 days from the germination, seedlings were exposed to a DC EF of $12.0 \mathrm{~V} \mathrm{~m}^{-1}$ with a current intensity of $10 \mathrm{~mA}$, according to Scopa et al. (2009). The EF was applied continuously for a period of five weeks, directly by a $50 \mathrm{~Hz}$ voltage set-up transformer (BIO-RAD Power-Pac 3000, Hercules, CA, USA), and monitored by a digital multimeter (model U1231A True RMS 6000; Agilent Technologies, CA, USA). Plants not subjected to the $\mathrm{EF}$, grown under the same conditions reported above in another identical polystyrene vessel, were kept as controls.

After 18 days from germination, electric conductivity (EC) and $\mathrm{pH}$ of the growing solution were measured using a conductivity meter (model HI 2316; Smithfield, RI, USA) and using a $\mathrm{pH}$ meter (model Jenway 4310; Barloworld Scientific T/As Jenway; Dunmow, Essex, England), respectively.

\section{Morphological analysis}

After five weeks from EF application, tomato plants were randomly selected next to the positive electrode (rows 1 and 2), in the central area (rows 6 and 7) and next to the negative electrode (rows 11 and 12) $(n=$ 10), respectively. The root system, from each plant, was cleaned and kept in an isotonic water solution to avoid drying. The fresh roots were mounted on slides and observed at different magnifications using a compound optical microscope (Eclipse 80i, Nikon, Tokyo, Japan) under transmitted light and then photographed (Digital Camera DS-Fil, Nikon, Tokyo, Japan). Images were analyzed (NIS-Elements Imaging Software, Nikon, Tokyo, Japan) to compare root morphology and evaluate descriptive parameters.
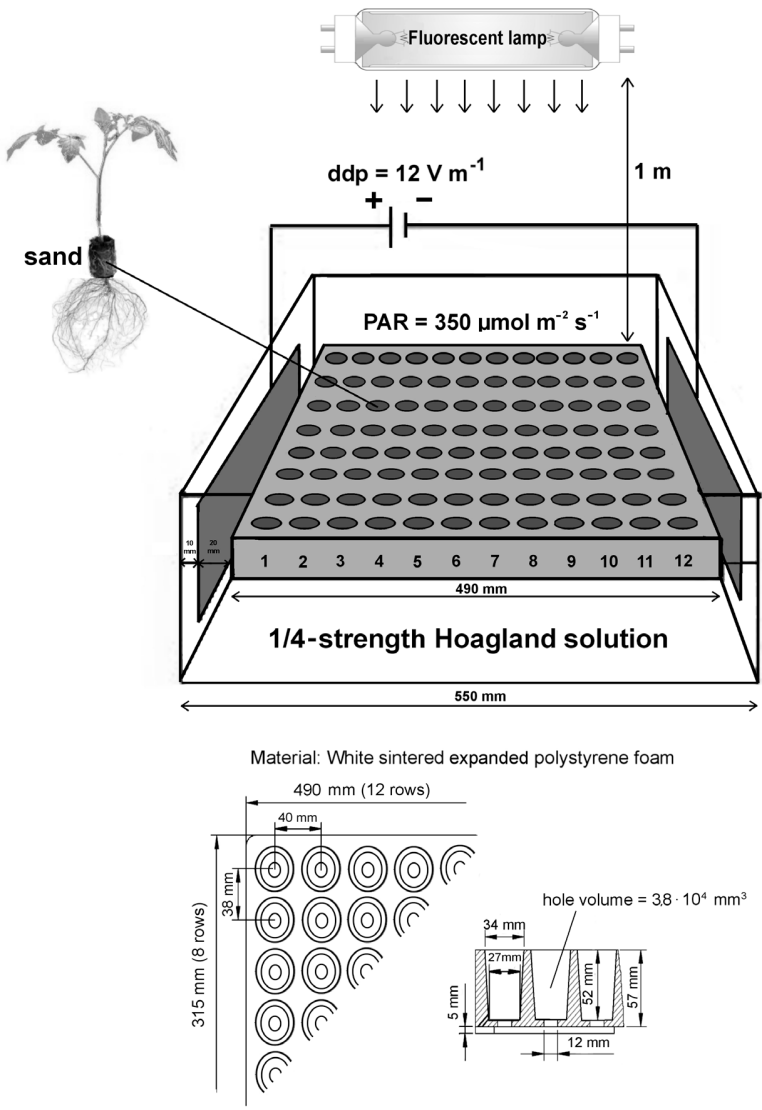

Fig. 1. Experimental system consisting of a floating polystyrene vessel with 96 holes. Tomato seedlings were maintained under controlled conditions at a constant temperature of $20^{\circ} \mathrm{C}$ with a $16 \mathrm{~h}$ photoperiod and a PAR of $350 \mu \mathrm{mol} \mathrm{m}^{-2} \mathrm{~s}^{-1}$ (measured at vessel level $=1 \mathrm{~m}$ from the lamps). ddp $=$ difference of electric potential.

Root apical meristems and root branching per plant were evaluated, and the means normalized to the main root axis length (mean number per $\mathrm{cm} \pm 20 \%$ error). Fresh and dry weights were measured for shoots and roots. The root/shoot ratio and the root length per unit of root mass (LRM) were so calculated.

Statistical analysis was performed by analysis of variance (ANOVA) with SAS software (SAS Institute, Cary, NC, USA). Significant differences were determined at $P \leq 0.01$, according to Fisher's LSD test. The same analyses reported above were carried out in control plants taken from the holes corresponding to those randomly chosen for the plants subjected to the EF.

\section{Results and Discussion}

Root morphology was strongly affected by the applied 


\section{A with EF}

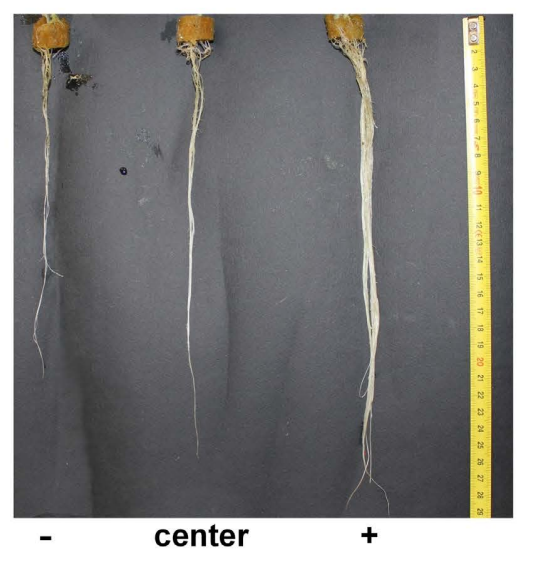

\section{B without EF}

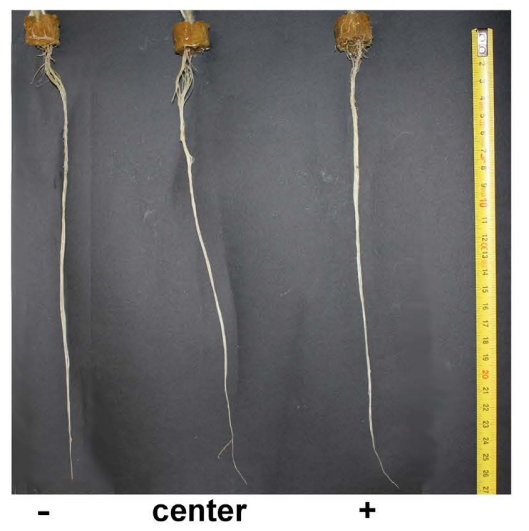

Fig. 2. Root morphology of tomato seedlings grown hydroponically under the electric field (A) and of the control plants not subjected to the electric field (B). Positions: (left; - ) negative electrode, (center) central area, (right; + ) positive electrode.

EF (Fig. 2). Indeed, a significant variation in shoot and root growth rate was observed among the groups of plants grown close to the positive/negative electrode or in the central part of the container (Fig. 2A and Table 1). Moreover, the average length of the main root of the plants subjected to the EF ranged from $21 \pm$ 1.5 (S.D.) $\mathrm{cm}$ next to the negative electrode, to $25 \pm$ 1.8 (S.D.) $\mathrm{cm}$ in the central part of the container, to 29 \pm 2.1 (S.D.) $\mathrm{cm}$ next to the positive electrode (Fig. 2A). This macroscopic observations were confirmed by the high values of both R/S and LRM of the plants subjected to the EF and sampled next to the positive electrode (Table 1), confirming their higher root length, growth and development. On the other hand, root morphology (Fig. 2B), R/S and LRM (Table 1) of control plants not subjected to the EF, taken from different vessel position, resembled the corresponding parameters of the plants under the EF taken in the
Table 1. Root/shoot ratio of dry weights $(\mathrm{R} / \mathrm{S})$ and length per unit root mass (LRM) of tomato seedlings grown hydroponically under the electric field (With EF) and of the control plants not subjected to the electric field (Without EF). Mean values $(n=10)$ with different letters are significantly different between treatments at $P \leq 0.01$, according to Fisher's LSD test.

\begin{tabular}{llll}
\hline Treatment & Position & R/S & $\begin{array}{c}\text { LRM } \\
\left(\mathrm{cm} \mathrm{g}^{-1}\right)\end{array}$ \\
\hline \multirow{2}{*}{ With EF } & + & $0.32 \mathrm{a}$ & $8492 \mathrm{a}$ \\
& Center & $0.27 \mathrm{~b}$ & $7849 \mathrm{~b}$ \\
& - & $0.24 \mathrm{c}$ & $6689 \mathrm{c}$ \\
\hline \multirow{2}{*}{ Without EF } & + & $0.28 \mathrm{~b}$ & $7728 \mathrm{~b}$ \\
& - & $0.27 \mathrm{~b}$ & $7692 \mathrm{~b}$ \\
& - & $0.27 \mathrm{~b}$ & $7810 \mathrm{~b}$ \\
\hline
\end{tabular}

central area of the container (Fig. 2A and Table 1).

Descriptive quantitative parameters determined microscopically were used to underline the differences observed (Fig. 3). Particularly, the tomato plants grown on the hand of the positive electrode, compared to the plants in the central area and towards the negative one of the container, showed pronounced root branching and hair development, and higher root density and length (Fig. 3A). Under EF exposure, the average number of root branches, normalized to root main axis length, increased from 0.3 branches $\mathrm{cm}^{-1}$, for the negative electrode, to 2.5 branches $\mathrm{cm}^{-1}$ next to the positive one (Fig. 4A). As for branching, apical meristems per $\mathrm{cm}$ reached the highest counting next to the positive electrode, approximately 4 apexes $\mathrm{cm}^{-1}$, against 3 apexes $\mathrm{cm}^{-1}$ in the central area, and 2 apexes $\mathrm{cm}^{-1}$ next to the negative electrode (Fig. 4B). Again, the microscopic parameters (Figs. 3B and 4) of all the control plants not subjected to the EF were not statistically different from the corresponding parameters of the plants subjected to the EF taken in the central area of the container (Figs. 3A and 4).

In the container without the $\mathrm{EF}$, the values of $\mathrm{EC}$ $(n=5)$ next to the positive electrode, in the central area and next to the negative electrode were $139.3 \pm$ 1.2 (S.D.), $139.1 \pm 0.9$, and $139.5 \pm 0.4 \mathrm{mS} \mathrm{m}^{-1}$ respectively, whereas the corresponding values under the EF were $138.9 \pm 3.4,142.1 \pm 4.9$, and $140.2 \pm 3.0$ $\mathrm{mS} \mathrm{m}{ }^{-1}$, and they were not statistically different $(P \leq$ 0.01, according to Fisher's LSD test) from the EC values without the EF. The values of $\mathrm{pH}$ of the growing solution $(n=5)$ measured in the container without the EF next to the positive electrode, in the central area and next to the negative electrode were $5.79 \pm 0.23$ (S.D.), $5.73 \pm 0.24$ and $5.73 \pm 0.16$, 


\section{A with EF}

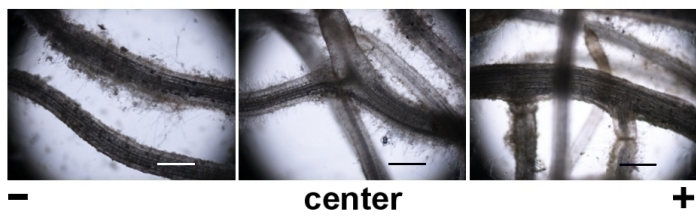

B without EF

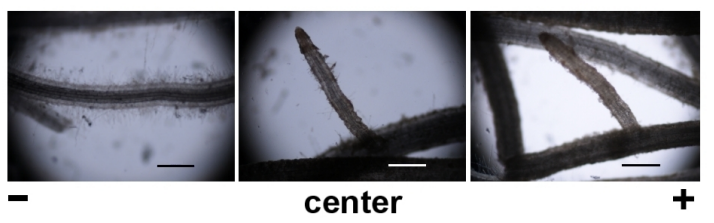

Fig. 3. Root banching of tomato seedlings grown hydroponically under the electric field (A) and of the control plants not subjected to the electric field (B).. Positions: (left; -) negative electrode, (center) central area, (right; +) positive electrode. Roots were observed at $0.02 \mathrm{~cm}$ from the tip using a compound optical microscope (Eclipse 80i, Nikon) under transmitted light at 40x magnification, and images photographed using a Digital Camera DS-Fil (Nikon). Scale bars $=0.5 \mathrm{~mm}$.

whereas the corresponding values under the EF were $6.33 \pm 0.35,5.70 \pm 0.32$ and $5.15 \pm 0.31$. In this case, the $\mathrm{pH}$ values measured at the positive and negative electrodes with and without the EF were statistically different, whereas the values in the central part did not statistically change $(P \leq 0.01$, according to Fisher's LSD test). As the values of EC of the growing solution did not change after the application of the EF, they could not be considered causes for the observed macroscopic and microscopic effects of the EF on the root growth and development. Under the $\mathrm{EF}, \mathrm{pH}$ was changed to 6.33 at the positive electrode and to 5.15 at the negative one, so alkalinization occurred at the positive electrode and acidification at the negative one. This may be one of the causes for the effects of EF on tomato root growth. Thus, the different growth patterns observed can be related to the different mineral gradients formed by migration of cations toward the negative electrode and anions toward the positive electrode in the water solution under the applied EF. In the presence of an EF, chemio-osmotic modifications of ion transport (an equivalent of salt influx or salt efflux driven at the expense of an equivalent of electrogenic proton efflux) could occur in roots (Robinson 1985). Furthermore, the increased ion accumulation seems not to be merely a passive movement under the applied potential, and it is thought that small currents could stimulate or inhibit active ion pumps or alter the internal distribution of
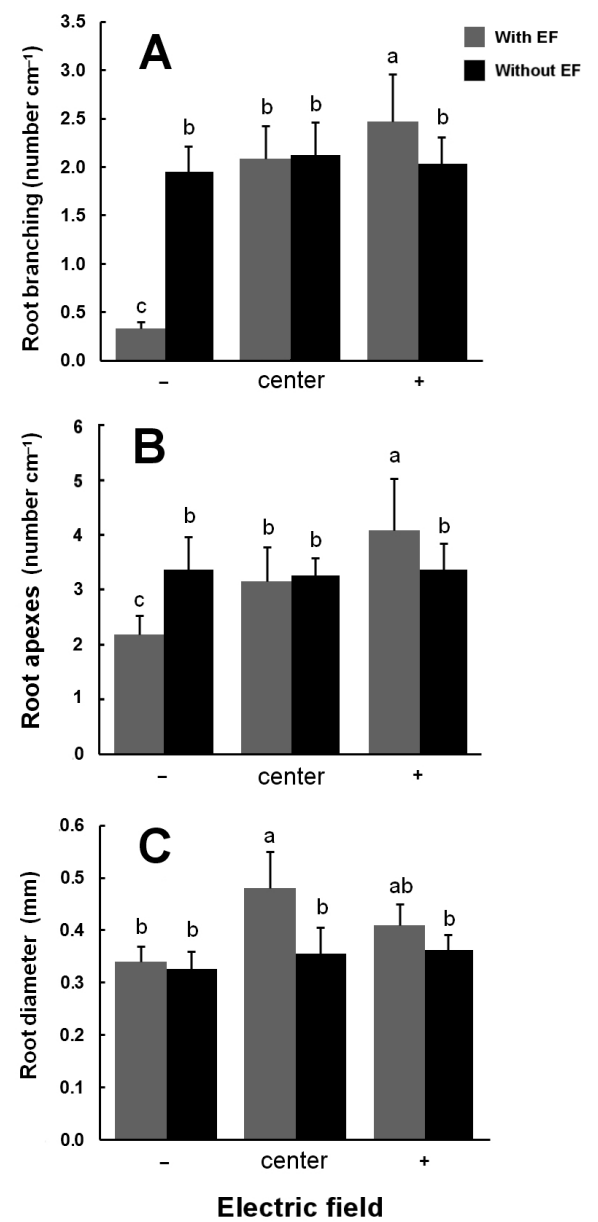

Fig. 4. (A) Total root branching, normalized to root main axis length (mean per $\mathrm{cm} \pm 20 \%$ error), and (B) total root apex number, normalized to root main axis length (mean per $\mathrm{cm} \pm 20 \%$ error), of tomato seedlings grown hydroponically under the electric field (grey columns) and of the control plants not subjected to the electric field (black columns). Positions: (left; -) negative electrode, (center) central area, (right; + ) positive electrode. Means $(n=10)$ with different same letters on the columns are significantly different $(P \leq$ $0.01)$ among the positions (-, centre, + ) of both the groups of plants, according to Fisher's LSD test.

growth-regulating compounds (Black et al. 1971, Robinson 1985).

An interesting observation could be related to another hypothesis: the root orientation in the growing medium. In fact, the "root direction" of our tomato plants was always well defined in the growing solution, as root growing direction was oriented towards the positive electrode. This curvature was not observed in the control plants. Electrotropic curvature in solutions of low electrolyte concentration was already studied using primary roots of maize (Ishikawa and Evans 1990). When submerged in 
oxygenated solution across which an EF was applied, the roots curved rapidly and strongly toward the positive electrode (Ishikawa and Evans 1990). These responses were controlled with auxin and auxin transport inhibitors (Goldsworthy and Rathore 1985, Ishikawa and Evans 1990). So, electrotropic curvature was probably due to a particular orientation and distribution of membrane proteins or to a different phytohormonal balance under the EF. In this regard, Brown and Loew (1994) found that EF-directed locomotion caused the lateral redistribution of plasma membrane glycoproteins in fibroblast cells, in vitro.

In conclusion, the root growth was affected by the positions under EF application. Roots were grown longer at the position close to the positive electrode, but the results were opposite in the roots close to the negative electrode. Indeed, the application of EF was not always positive, in terms of growth acceleration, against the root growth at every position under EF, as half of the hydroponically-cultivated plants were affected negatively. These results point to a possibility of applying electric fields for controlling tomato root growth. Next experimentation should investigate the cause mechanisms by which the application of EFs, varying in current intensity and voltage, and the consequent changes in $\mathrm{pH}$ of the growing solution can cause the morphological changes observed in tomato roots.

\section{Acknowledgments}

We are grateful to Prof Mariana Amato and Dr Rocco Bochicchio for their important suggestions about the manuscript.

\section{References}

Black J D, Forsyth F R, Fensom D S, Ross R B 1971 Electrical stimulation and its effects on growth and ion accumulation in tomato plants. Can. J. Bot. 49: 1809-1815.

Brown M J, Loew L M 1994 Electric field-directed fibroblast locomotion involves cell surface molecular reorganization and is calcium independent. J. Cell Biol. 127: 117-128.

Goldsworthy A, Rathore K S 1985 The electrical control of growth in plant tissue cultures: the polar transport of auxin. J. Exp. Bot. 36: 1134-1141.

Hamada S, Ezaki S, Hayashi K, Toko K, Yamafuji K. 1992 Electric current precedes emergence of a lateral root in higher plants. Plant Physiol. 100: 614-619.

Ishikawa H, Evans M L 1990 Electrotropism of maize roots. Plant Physiol. 94: 913-918.

Nechitailo G, Gordeev A 2004 The use of an electric field in increasing the resistance of plants to the action of unfavorable space flight factors. Adv. Space Res. 34: 1562-1565.

Robinson K R 1985 The responses of cells to electrical fields: a review. J. Cell Biol. 101: 2023-2027.

Scopa A, Colacino C, Barone Lumaga M R, Pariti L, Martelli G. 2009 Effects of a weak DC electric field on root growth in Arundo donax (Poaceae). Acta Agr. Scand B-SP. 59: 481-484.

Wawrecki W, Zagórska-Marek B 2007 Influence of a weak DC electric field on root meristem architecture. Ann. Bot. 100: 791-796.

Wolverton C, Mullen J L, Ishikawa H, Evans M L 2000 Two distinct regions of response drive differential growth in Vigna root electrotropism. Plant Cell Environ. 23: $1275-1280$

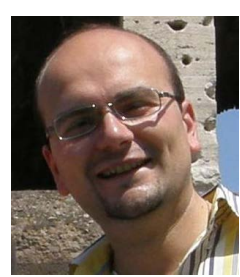

Dr. Giuseppe Tataranni is a biotechnologist. His activity has been mainly focussed on molecular biology, pharmacology, cancer research, and plant physiology. $\mathrm{He}$ is contract researcher and professor in ecology.

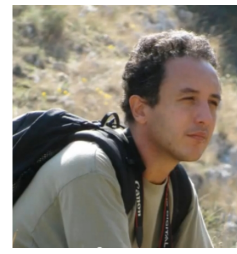

Dr. Adriano Sofo studies plant roots by molecular and physiological approaches at Basilicata University. $\mathrm{He}$ is interested in the relationships between soil and plants, particularly in sustainable agronomic systems.

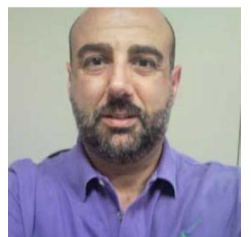

Prof. Cristiano Casucci is an agricultural chemist interested in soil fertility and plant-soil interactions. He studies the effects of xenobiotic compounds on soil microbial diversity and soil enzymes activity.

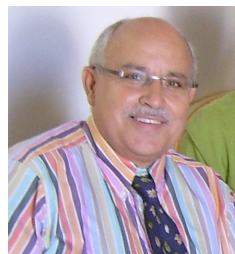

Prof. Antonio Scopa is an agricultural chemist of Basilicata University, Potenza, Italy. He is interested in the adaptation of plants to abiotic stresses, such as electricity and UV radiation. 